\section{Secondary metabolites from Penicillium roqueforti, a starter for the production of Gorgonzola cheese}

\author{
Lisa Vallone, ${ }^{1}$ Alberto Giardini, ${ }^{2}$ \\ Gabriella Soncini \\ 'Dipartimento di Scienze Veterinarie per \\ la Salute, la Produzione Animale e la \\ Sicurezza Alimentare, Università di \\ Milano; ${ }^{2}$ Centro Sperimentale del Latte \\ S.r.I., Zelo Buon Persico (LO), Italy
}

\section{Abstract}

The presence of mold in food, although necessary for production, can involve the presence of secondary metabolites, which are sometimes toxic. Penicillium roqueforti is a common saprophytic fungus but it is also the essential fungus used in the production of Roquefort cheese and other varieties of blue cheese containing internal mold. The study was conducted on industrial batches of Penicillium roqueforti starters used in the production of the Gorgonzola cheese, with the aim to verify the production of secondary metabolites. Nine Penicillium roqueforti strains were tested. The presence of roquefortine $\mathrm{C}, \mathrm{PR}$ toxin and mycophenolic acid was tested first in vitro, then on bread-like substrate and lastly in vivo in nine cheese samples produced with the same starters and ready to market. In vitro, only Penicillium out of nine produced roquefortine $\mathrm{C}$, four starters showed mycophenolic acid production, while no significant amounts of PR toxin were detected. In the samples grown on bread-like substrate, Penicillium did not produce secondary metabolites, likewise with each cheese samples tested. To protect consumers' health and safety, the presence of mycotoxins needs to be verified in food which is widely consumed, above all for products protected by the protected denomination of origin (DOP) label (i.e. a certificate guaranteeing the geographic origin of the product), such as Gorgonzola cheese.

\section{Introduction}

The genus Penicillium is widespread in nature and grows in many different habitats. Most Penicilli are ubiquitous and generally they are saprophytic organisms with significant usage in the industrial mycology for antibiotics (such as penicillin and griseofulvin) and enzymes (such as ribonuclease) production, but they are also known as spoilage agents in the food industry.

Penicillium roqueforti, a species especially known for its involvement in silage contaminations, is also commonly involved in the spoilage of hard, semi-hard and soft-cheeses (Filtenborg et al., 1996; Kure and Skaar, 2000; Kure et al., 2004). However, selected strains of $P$. roqueforti are used in food manufacture and play a decisive role in the ripening of some cheeses, such as Gorgonzola, Roquefort, Stilton and Danablu. Inoculating the milk with pure cultures of $P$. roqueforti is essential to obtain the characteristic flavours and aromas of these cheeses, due to the strong lipolytic activity of the moulds and to the production of short chain fatty acids (acetic, butyric, caprylic, and caproic acid). Fatty acids are oxidised to produce methylketone, which improves flavour (Caridi, 1996; Tiecco, 2001). Typically, in spicy Gorgonzola and blue cheeses production, $P$. roqueforti is used as a unique culture. In sweet Gorgonzola production, $P$. glabrum and $P$. crustosum cultures are used on their own or in association with $P$. roqueforti. The use of different mixtures of Penicilli confers the bluegreen marbling characteristics and creaminess of each particular cheese (Finoli et al., 2001). However, some species of Penicillium can produce toxic metabolites. The toxigenicity of Penicillium species is known about since 1913 , when penicillic acid was isolated from cultures of $P$. puberulum Bain (Frisvad and Filtemborg, 1989). $P$. roqueforti is known to produce the following toxins: roquefortine $\mathrm{C}$, PR-toxin, patulin, penicillic acid, mycophenolic acid and isofumigaclavine A and B (Frisvad $e t$ al., 2004; 0'Brien et al., 2006).

\section{Roquefortine C}

Roquefortine is an alkaloid with neurotoxic activity that causes paralysis in guinea pigs. Roquefortine has antibacterial properties and is Ames test negative. There are no studies of its toxicity in laboratory animals that meet good laboratory practice standards. Older data suggest roquefortine toxicity (ip) is in the range of $15-100 \mathrm{mg} / \mathrm{kg}$ of body weight (Scott, 1984). Arnold et al. (1987) report an oral $\mathrm{LD}_{50}$ of $169 \mathrm{mg} / \mathrm{kg}$ in male and $184 \mathrm{mg} / \mathrm{kg}$ in female CR57 mice and a similar value for male and female Swiss Webster mice. The data on neurotoxicity of roquefortine are equivocal (Fog Nielsen et al., 2006). Several studies have revealed the presence of roquefortine $\mathrm{C}$ in blue-veined cheeses (Ohmomo et al., 1975; Scott and Kennedy, 1976; Ware et al., 1980; López-Díaz, 1996). Finoli et al. (2001) reported roquefortine $\mathrm{C}$ concentrations ranging from 50 to $1470 \mu \mathrm{g} / \mathrm{kg}$ after analysis of 30 blue-cheeses. Kokkonen et al. (2005) showed that the concentration of this metabolite ranged from 600 to $12,000 \mu \mathrm{g} / \mathrm{kg}$ in 9 blue cheeses.
Correspondence: Lisa Vallone, Dipartimento di Scienze Veterinarie per la Salute, la Produzione Animale e la Sicurezza Alimentare, Università di Milano, via Grasselli 7, 20137 Milan, Italy. Tel. +39.02 .50318511 - Fax: +39.02 .50318501 . E-mail: lisa.vallone@unimi.it

Key words: Cheese, Penicillium roqueforti, Roquefortine C, PR toxin, Mycophenolic acid.

Conflict of interests: the authors declare no potential conflict of interests.

Received for publication: 18 November 2013.

Revision received: 27 January 2014.

Accepted for publication: 27 January 2014.

This work is licensed under a Creative Commons Attribution 3.0 License (by-nc 3.0).

(C) Copyright L. Vallone et al., 2014

Licensee PAGEPress, Italy

Italian Journal of Food Safety 2014; 3:2118

doi:10.4081/ijfs.2014.2118

\section{PR-toxin}

PR-toxin is one of the metabolites produced by $P$. roqueforti having acute toxicity (Scott, 1984): it is lethal to rats, mice, and cats and is mutagenic in the Ames test (Fog Nielsen et al., 2006). In mice, the ip $\mathrm{LD}_{50}$ is $5.8 \mathrm{mg} / \mathrm{kg}$ (Chen et al., 1982). It has often been found in marbled cheeses (Wei et al., 1985). Polonelli et al. (1982) speculate that microaerophilic condition prevails in most cheeses, which may explain why the PR-toxin is not generally found in the final product. However, PR-toxin is unstable because it quickly reacts with nitrogen compounds such as ammonia and ammonia salts, amino acids (lysine and cysteine), amines, casein and the decomposition products resulting in a less toxic PR imine (Erdogan et al., 2003).

\section{Patulin}

Patulin is a toxic secondary metabolite produced by certain species of the genera Aspergillus, Penicillium, and Byssochlamys. It is considered neurotoxic, embryotoxic and teratogenic (Dombrink-Kurtzman and Blackburn, 2005) and has been classified by IARC as category 3 unclassifiable as to carcinogenicity in humans; the evidence for carcinogenicity of patulin in experimental animals is considered inadequate and the results of genotoxicity tests are non-conclusive (IARC, 1986). The carcinogenic activity in different animal models is still the subject of some controversy (Schumacher et al., 2006). The $\mathrm{LD}_{50}$ of patulin ranges from 15 to $25 \mathrm{mg} / \mathrm{kg}$ and varies with animal species and route of exposure (Yang et al., 2014). Few studies on the presence of this mycotoxin in cheese have been published: by Spanish (López-Diaz et al., 1996), by Turkish 
(Erdogan et al., 2003) and by Italian researchers (Pattono et al., 2013).

\section{Penicillic acid}

Penicillic acid is a lactone substance and possesses a wide range of toxic properties including carcinogenicity (Klari Šegvi et al., 2013). However, IARC classified penicillic acid as belonging to Group 3, which means that penicillic acid is not carcinogen to humans (IARC, 1998). Studies on experimental animals revealed that penicillic acid induces significant hepatobiliary excretory dysfunction in mouse and rats, while it did not provoke significant damage to internal organs in chickens. The toxin has a $L_{50}$ of $100 \mathrm{mg} / \mathrm{kg}$ by subcutaneous injection in mice (Sansing et al., 1976). The production of penicillic acid has been highlighted in two strains out of six selected among fungal isolates from Cheddar cheese starter (Moubasher et al., 1978).

\section{Mycophenolic acid}

Mycophenolic acid is a metabolite produced by $P$. roqueforti and other species of Penicillium (Lafont et al., 1979). Because of its use as a human drug, mycophenolic acid is best understood. It is antibacterial and immunosuppressive in animals: acute toxicity and mutagenic effects have been described for chickens, mice, rats and rabbits (Engel et al., 1982; Kajiwara et al., 1982). The toxin has a $\mathrm{LD}_{50}$ of $450 \mathrm{mg} / \mathrm{kg}$ by e.g. in rat (Bentley, 2000). Furthermore, it has been found to occur naturally in some blue cheeses and in silage (Fog Nielsen et al., 2006). Zambonin et al. (2002) found mycophenolic acid concentrations ranging from 100 to 500 $\mu \mathrm{g} / \mathrm{kg}$ in 5 samples of Gorgonzola and Danablu. Usleber et al. (2008) investigated the occurrence of mycophenolic acid in 53 blue-cheeses and found that the levels of this mycotoxin varied from $<10$ to $1200 \mu \mathrm{g} / \mathrm{kg}$ for blue-veined cheeses while a blue-white mold cheese contained $11,000 \mu \mathrm{gg} / \mathrm{kg}$.

\section{Isofumigaclavine (A-B)}

Isofumigaclavine $\mathrm{A}$, an alkaloid, and its hydrolysis product, isofumigaclavine $\mathrm{B}$, are identical to Roquefortine A and B, respectively. Most of the physical properties reported for Roquefortine A (Ohmomo et al., 1975) are similar to those of isofumigaclavine A and the Authors may be the same compound. However, isofumigaclavine $\mathrm{B}$, obtained by hydrolysis of isofumigaclavine $\mathrm{A}$, had a higher melting point than that reported for Roquefortine B (Scott and Kennedy, 1976). The toxicological effects of these substances are not well known, but some neurotoxic data are described by Ohmomo et al. (1975), Scott (1984), and Scott et al. (1976). Isofumigaclavine A (average 0.61 $\mu \mathrm{g} / \mathrm{g}$ ) and traces of Isofumigaclavine $\mathrm{B}$, were found in 16 samples of marbled cheese (Scott and Kennedy, 1976). A similar study detected low levels of Isofumigaclavine A and B in blue cheese (0'Connor and 0'Brien, 2000). Based on these bibliographic evidence, the aim of this study was to evaluate the potential production of secondary metabolites by fungal starters used in the production of Gorgonzola cheese.

\section{Materials and Methods}

The study was conducted on nine industrial batches of five Penicillium roqueforti starters used in the production of the Gorgonzola cheese. The batches were all produced by the Centro Sperimentale del Latte S.r.l. [(Zelo Buon Persico (LO), Italy)] and were named: PV 11104, NON 11203, PV 10704, NOC 09203, NON 10803, NON 10804, NOPC 09103, NOPC 10902, and PY 10604. The strains composition of each of the five starters (PV, NON, NOC, NOPC, and PY) was characterised by PCR technique (data not shown). The $P$. roqueforti metabolites of interest were: $\mathrm{PR}$ toxin, roquefortine $\mathrm{C}$ and mycophenolic acid. The research was carried out in three steps. Step A (in vitro studies), detection of fungal secondary metabolites in laboratory culture medium. Step B (in vitro studies), detection of fungal secondary metabolites in samples of industrial culture medium (breadlike), that is on the substrate and in conditions in which the strains of $P$. roqueforti are industrially grown. Step C (in vivo studies), detection of fungal secondary metabolites on nine randomised samples of Gorgonzola cheese, produced with the above-mentioned starters and collected after at least 60 days of ripening (i.e. cheese ready to market).

\section{Step A: in vitro studies on labora- tory culture medium}

Following the method suggested by Frisvad and Thrane (1987), the spores of each fungal strain are spread on eight Petri plates containing CYA (Czapek Yeast Agar; Merck, Darmstadt, Germania) and incubated at $25^{\circ} \mathrm{C}$ for 14 days, in the dark. The whole contents of the plates were transferred in polyethylene bags and the secondary metabolites were extracted with $150 \mathrm{~mL}$ of chloroform-methanol $(2: 1, \mathrm{v} / \mathrm{v})($ Merck) in a stomacher for $3 \mathrm{~min}$ and filtered through Whatman $\mathrm{N}^{\circ} 1$ paper. After addition of $1 \mathrm{~mL}$ of phosphoric acid (85\%) (Merck) and filtration through Whatman $\mathrm{N}^{\circ} 1$ paper, the fungal cultures were extracted with acetone-ethyl acetate (1:1, v/v) (J.T.Baker Chemicals, Center Valley, PA, USA) and filtered through Whatman $\mathrm{N}^{\circ} 1$ paper once more by suction. The latter liquid fraction was refiltered through a Whatman 1 PS phase separator filter and the organic phases were evaporated in vacuum at $40^{\circ} \mathrm{C}$ on a rotary evaporator. The residue was taken up in $3 \mathrm{~mL}$ of methanol and washing twice with petroleum ether (Merck).
The lower secondary metabolite-containing methanol phase was filtered through disposable filters $(0.45 \mu \mathrm{m})$ before injection. Several alkylphenones (acetophenone, propiophenone, butyrophenone, hexanophenone, valerophenone, octanophenone, decanophenone; Sigma Aldrich, St. Louis, MO, USA) are used as internal standards and are injected on a 100 $\mathrm{mm}$ x $4 \mathrm{~mm}$ I.D. Nucleosil $5 \mu \mathrm{m} \mathrm{C}_{18}$ column (Waters Corporation, Milford, MA, USA) of HPLC with diode-arrays detector (Hplc and diode- arrays detector system; Shimadzu, Kyoto, Japan), initially in pure form and then mixed at the fungal extract of each plate. The mobile phases are the same pointed out by Frisvad (Frisvad and Thrane, 1987). All metabolites were detected at $225 \mathrm{~nm}$.

Both for detected alkylphenones and secondary metabolites, the retention index (RI) is calculated from the following equation:

$$
\mathrm{RI}=\frac{(\mathrm{Tsm}-\mathrm{Tp} 1) \Delta \mathrm{z} * 100}{\mathrm{Tp} 2-\mathrm{Tp} 1}+\mathrm{z} * 100
$$

where Tsm=retention time of the secondary metabolite, Tpl=retention time of the alkylphenone that elutes before the secondary metabolite, Tp2=retention time of the alkylphenone that elutes after the secondary metabolite, $\mathrm{z}=$ number of carbon atoms in the alkylphenone that elutes before the secondary metabolite and $\Delta \mathrm{z}=$ difference between the number of carbon atoms in the alkylphenones that elute before and after the secondary metabolite. All the reagents were Hplc grade. The injections were performed in duplicate.

\section{Step B: in vitro research on bread substratum}

The secondary metabolites are extracted from the bread substratum through the same preceding steps, exploiting the solvents in the same way and using the same alkylphenones.

\section{Step C: in vivo research}

The cheese analysis was carried out by specific methods for the detection of the three metabolites, separately processing the same samples three times. The methods are described as follows.

For mycophenolic acid: a $25 \mathrm{~g}$ portion of cheese was homogenised with $50 \mathrm{~mL}$ of $5 \%$ aqueous $\mathrm{NaCl}$ in an ultraturrax for 2 min. After addition of $150 \mathrm{~mL}$ of methanol- $\mathrm{CHCl}_{3}$ (1:1, $\mathrm{vol} / \mathrm{vol})$ (Merck), the mixture was homogenised for $3 \mathrm{~min}$ and filtered, and the filtrate was stored overnight at $-20^{\circ} \mathrm{C}$. The precipitated casein was removed by centrifugation (10 min, $5.000 \mathrm{xg}$ ). The supernatant was evaporated to about $100 \mathrm{~mL}$ in a rotary evaporator, quantitatively transferred into a funnel, and extracted three times with $100 \mathrm{~mL}$ of n-hexane (Merck) each time. This defatted aqueous phase was consecutively extracted with two 100 -mL portions of $\mathrm{CHCl}_{3}, 100 \mathrm{~mL}$ of $\mathrm{CHCl}_{3}$-ethyl acetate 
(1:1, vol/vol) (Merck), and finally $100 \mathrm{~mL}$ of ethyl acetate. The combined extracts were dried with sodium sulfate (J.T.Baker Chemicals), evaporated to dryness, dissolved in $\mathrm{CHCl}_{3}$, transferred quantitatively into a screw-cap vial, evaporated under nitrogen to dryness, and dissolved in $125 \mu \mathrm{L}$ of $\mathrm{CHCl}_{3}$ (Engel et al., 1982). For PR-toxin: a 50 g portion of cheese was homogenised with $250 \mathrm{~mL}$ of methanol-water (55:45 vol/vol) (Merck) and with $150 \mathrm{~mL}$ of hexane (Merck) in an waring blender for $5 \mathrm{~min}$ at high speed. The obtain emulsion was centrifuged (10 min, 4000xg, $4^{\circ} \mathrm{C}$ ). After removing the hexane layer, the methanol-water part was vacuum-filtered through Whatman $\mathrm{N}^{\circ} 3$ paper and the resultant filtrate was extracted with two 60 -mL volumes of chloroform. The two chloroform extracts from each portion were pooled, added with 10 g anhydrous $\mathrm{Na}_{2} \mathrm{SO}_{4}$ (J.T.Baker Chemicals) and evaporated to dryness using a rotary evaporator at $37^{\circ} \mathrm{C}$. The dried extract was dissolved with chloroform and cleaned up by a LiChrolut SPE Si 2024 silica gel column (Merck) eluted with $2 \mathrm{~mL}$ of mixture of hexane and ethyl acetate (J.T.Baker Chemicals). The residues were reduce to dryness under gentle nitrogen stream and dissolved in $100 \mu \mathrm{L}$ of $\mathrm{CHCl}_{3}$ (Siemens and Zawistowski, 1992). For roquefortine $\mathrm{C}$ : a $50 \mathrm{~g}$ portion of cheese was homogenised with $10 \mathrm{~g}$ of celite (J.T.Baker Chemicals) and $250 \mathrm{~mL}$ of ethyl acetate in an waring blender for $5 \mathrm{~min}$ at high speed. The extract was filtred throught Whatman $\mathrm{N}^{\circ}$. 1 paper and added with $50 \mathrm{~mL}$ of $\mathrm{HCl}(0.01 \mathrm{~N})$ (J.T.Baker Chemicals). After a gentle agitation fo $20 \mathrm{sec}$, the watery phase was recovered and the organic phase was extracted a second time with $50 \mathrm{~mL}$ of acid solution. The two extract were defatted with $50 \mathrm{~mL}$ of hexane. At the watery phase was addeded $50 \mathrm{~mL}$ of $3 \%$ $\mathrm{NaHCO}_{3}$ (Merck) and it was extracted twice with $50 \mathrm{~mL}$ of ethyl acetate. At the two organic phases were addeded with $10 \mathrm{~g}$ of $10 \mathrm{~g}$ anhydrous $\mathrm{Na}_{2} \mathrm{SO}_{4}$ (J.T.Baker Chemicals), shaked for 10' and evaporated to dryness using a rotary evaporator at $37^{\circ} \mathrm{C}$. The dried extract was dissolved with chloroform, reduce to dryness under gentle nitrogen stream and dissolved in $100 \mu \mathrm{L}$ of $\mathrm{CHCl}_{3}$ (Ware et al., 1980).

The analysis was performed in HPLC with diode array detection (Hplc and diode-arrays detector system; Shimadzu). The column was a $100 \mathrm{~mm}$ x $4 \mathrm{~mm}$ I.D. Nucleosil $5 \mu \mathrm{m} \mathrm{C}_{18}$ column (Waters Corporation). All the reagents were Hplc grade. The extracted metabolites were finally detected by following the above-mentioned method (Frisvad and Thrane, 1987). The analyses were performed in duplicate.

\section{Results}

\section{Step A: in vitro research}

As regards the strains analysed in vitro, only two strains out of nine produced Roquefortine C (NON 10803 and PY 10604). Mycophenolic acid was drawn out from four strains (NON 10803; NON 11203; NON 10804; NOPC 09103); PR toxin was not detected in any of the strains analysed in our study.

\section{Step B: research on bread-like samples}

In this stage of the study, there was no evidence of the production of metabolites from the Penicillium tested. The substratum breadlike may not have had right characteristics to allow or support the production of mycotoxins from these moulds.

\section{Step C: in vivo research}

Secondary metabolites were not detected in any of the cheese samples analysed, although we applied metabolite-specific methodologies.

\section{Discussion}

The results of the analyses indicate that the strains of Penicillium roqueforti tested were only able to produce secondary metabolites in vitro. Roquefortine $\mathrm{C}$ and mycophenolic acid are the only secondary metabolites that the strains of Penicillium roqueforti tested produced in culture, in agreement with 0'Brien et al. (2006) and Fog Nielsen et al. (2006), only on CYA medium. Our in vivo tests produced no positive results. The qualitative and quantitative mycotoxin profile, which a mould produces on a food commodity, really depends on the ecological and processing parameters of the particular foodstuff (Filtenborg et al., 1996) and can therefore be expected to be different from synthetic media.

The Penicillium roqueforti studied are very easily developed on the industrial culture medium bread-like (CSL Laboratory uses this substratum bread-like for the growth of the $P$. roqueforti and to produce suspensions of spores). Due to its resistance to organic acids and ability to grow at low $\mathrm{pH}, P$. roqueforti is found as a contaminant of processed food such as bread, rye bread (Fog Nielsen et al., 2006), even if the dominant spoilage flora varies with the type of bread and the storage temperature. Mycotoxigenic moulds can be isolated from spoiled breads, and many mycotoxins have been produced in inoculated breads, but naturally the toxins are mainly aflatoxins, ochratoxin A, Fusarium toxins.

On cheese's samples too, our research did not provide any results: the strains of
Penicillium tested did not produce secondary metabolites. Similar results have been obtained by several authors, who observed that mould strains grown in cheese did not produce metabolites even though they belonged to potentially toxigenic species. Note that the production of secondary metabolites from moulds is a strain specific characteristic, and toxigenic strains cannot be differentiated from non-toxigenic strains by morphological characteristic alone. Therefore, a fungal species is referred to as potentially toxigenic, which indicates that some strains may produce toxic metabolites. Indeed, in order to test the presence or absence of secondary metabolites in a food sample, it is essential to let the strains grow under suitable conditions. In fact, the production of mycotoxins depends on the substrate, which is particularly important for the mould strains used in food production (Scott and Kanhere, 1979). In reality, the strains tested in this study behaved differently in laboratory medium, in industrial medium and in cheese.

Additionally, toxigenic moulds are believed to represent a minor proportion of the total flora in cheese and cheese factory environments: the fungal metabolism is affected by environmental factors such as temperature, water activity, $\mathrm{pH}$, substrate, strains of moulds, gas composition, microbial interactions (competitive bacterial or other fungal species). Several experiments applying techniques of molecular biology have investigated the influence of these parameters on the expression of mycotoxin biosynthesis genes and have shown that the effect of external factors on mycotoxin biosynthesis is exerted at the level of transcription (Schmidt-Heydt et al., 2008). As expected, PR-toxin was not detected in cheese because of its reactivity with nitrogen compounds, as previously described. Indeed, cheese is not necessarily a good substrate for mycotoxin formation and some mycotoxins (like penicillic acid and PR toxins) have been shown to be unstable in the cheese matrix (Kokkonen et al., 2005; Boysen et al., 1996).

Regarding roquefortine $\mathrm{C}$, our results differ from similar research: Kokkonen et al. (2005) detected this metabolite in all the ten cheese samples analysed, with quantities ranging from 0.8 to $12 \mu \mathrm{g} / \mathrm{kg}$. Similar results were obtained by Schoch et al. (1984a, 1984b) and Finoli et al. (2001). On the other hand, our results are in agreement with other studies show that strains of Penicillium roqueforti isolated from cheeses produced only PR toxin and penicillic acid (Van Egmond, 1989), or only patulin and penicillic acid (Wei Yun et al., 1988). The production of roquefortin $C$ seems to be influenced by many factors including the amount of $\mathrm{NaCl}$ in the substrate, the ripening time of the cheese and the intervals between the punctures (usually after 20-30 days), 
because an increasing puncturing rate introduces more oxygen into the cheese to help the growth of moulds.

\section{Conclusions}

In order to reduce the presence of secondary metabolites in blue cheeses, one of the methods suggested by several authors is the use of strain with low productive ability (Engel and Teuber, 1989; Moss, 1992; Lafont et al., 1990; Pose et al., 2007). Buzilova et al. (2000) have studied the effect of mutation on synthesis of alkaloid by Penicillium roquefortii VKM F-141. The study has shown that the Penicilli mutants were unable to synthesise alkaloids or they changed the alkaloid composition. Puel et al. (2007) have shown that the ability to produce patulin from Byssochlamys fulva is related to presence/absence of two genes.

The latest techniques of molecular biology should be used to detoxify foods by secondary metabolites, identifying and removing genes responsible for the mycotoxin synthesis, in order to prevent its production (Gigliotti and Verga, 2007). Currently this is only possible for some secondary metabolites but in our opinion these techniques could be transferred to other species. This will be possible only through a more extensive understanding of fungal genomes.

\section{References}

Arnold DL, Scott PM, McGuire PF, Harwig J, 1987. Acute toxicity studies on roquefortine $\mathrm{C}$ and PR-toxin, metabolites of Penicillium roqueforti in the mouse. Food Cosmet Toxicol 16:369-71.

Bentley R, 2000. Mycophenolic acid: a one hundred year odyssey from antibiotic to immunosuppressant. Chem Rev 100:3801-25.

Boysen M, Skouboe P, Frisvad JC, Rossen L, 1996. Reclassification of the Penicillium roqueforti group into three species on the basis of of molecular genetic and biochemical profiles. Microbiology 142:541-9.

Buzilova IG, Boichenko DM, Bolchenko LV, Zelenkova NF, Arinbasarov MU, Baskunov BP, Reshetilova TA, 2000. Effect of mutation on synthesis of alkaloid by Penicillium roquefortii VKM F-141 and P. fellutanum VKM F-1073. Appl Biochem Micro+ 36:276-81.

Caridi A, 1996. Biotecnologie microbiche ed alimenti: il ruolo delle muffe nella maturazione dei formaggi. Helios Magazine 3:245.

Chen FC, Chen CF, Wei RD, 1982. Acute toxicity of PR toxin, a mycotoxin from
Penicillium roqueforti. Toxicon 20:433-41.

Dombrink-Kurtzman MA, Blackburn JA, 2005. Evaluation of several culture media for production of patulin by Penicillium species. Int J Food Microbiol 98:241-8.

Engel G, Teuber M, 1989. Toxin metabolites from fungal cheese starter cultures. In: Van Egmond, ed. Mycotoxins in dairy products. Elsevier, London, pp 163-92.

Engel G, Von Milczewski KE, Prokopek D, Teuber M, 1982. Strain specific synthesis of mycophenolic acid by Penicillium roqueforti in blue-veined cheese. Appl Environ Microb 43:1034-40.

Erdogan A, Gurses M, Sert S, 2003. Isolation of moulds capable of producing mycotoxin from blue mouldy Tulum cheeses produced in Turkey. Food Microbiol 85:83-5.

Filtenborg 0, Frisvad JC, Thrane U, 1996. Moulds in food spoilage. Int $\mathrm{J}$ Food Microbiol 33:85-102.

Finoli C, Vecchio A, Galli A, Dragoni I, 2001. Roquefortine $\mathrm{C}$ occurrence in blue cheese. J Food Protect 64:246-51.

Fog Nielsen K, Nielsen OG, Sumarah MW, Frisvad JC, Miller JD, 2006. Production of metabolites from the Penicillium roqueforti complex. J Agr Food Chem 54:3756-63.

Frisvad JC, Filtemborg 0, 1989. Terverticillate Penicillia: chemotaxonomy and mycotoxins production. Mycologia 81:837-61.

Frisvad JC, Smedsgaard J, Larsen T0, Samson RA, Robert A, 2004. Mycotoxins, drugs and other extrolites produced by species in Penicillium subgenus Penicillium. Stud Mycol 49:201-41.

Frisvad JC, Thrane U, 1987. Standardized HPLC of 182 mycotoxins and other fungal metabolites based on alkylphenone retention indices and UV-Vis spectra (diode array detection). J Chromatogr 404:195214.

Gigliotti C, Verga B, 2007. Biotecnologie alimentari. Piccin-Nuova Libraria, Padova, Italy.

IARC, 1986. Patulin. IARC Monog Eval Carc 40:83-98.

IARC, 1998. Penicillic acid in some naturally occurring substances. IARC Monog Eval Carc 10:21.

Yang J, Li J, Jiang Y, Duan X, Qu H, Yang B, Chen F, Sivakumar D, 2014. Natural occurrence, analysis, and prevention of mycotoxins in fruits and their processed products. Crit Rev Food Sci 54:64-83.

Kajiwara Y, Kimura T, Kanbara T, Kuriyama T, Naito Y, Yoshida S, Akaboshi S, Ito R, 1982. Species differences of mycophenolic acid, a new drug for psoriasis, in acute, subacute, and chronic toxicity. Toho Igakkai Zasshi 29:400-11.

Klari Šegvi M, Raši D, Peraica M, 2013. Deleterious effects of mycotoxin combinations involving ochratoxin A. Toxins
5:1965-87.

Kokkonen M, Jestoi M, Rizzo A, 2005. Determination of selected mycotoxins in mould cheeses with liquid chromatography coupled to tandem with mass spectrometry. Food Addit Contam 22:449-56.

Kure CF, Skaar I, 2000. Mould growth on the Norwegian semi-hard cheeses Norvegia and Jarlsberg. Int J Food Microbiol 62:1337.

Kure CF, Skaar I, Brendehaug J, 2004. Mould contamination in production of hard cheese. Int J Food Microbiol 15:41-9.

Lafont P, Debeaupuis JP, Gaillardin M, Payen J, 1979. Production of mycophenolic acid by Penicillium roqueforti strains. Appl Environ Microb 37:365-8.

Lafont P, Siriwardana MG, DeBoer E, 1990. Contamination of dairy products by fungal metabolites. J Environ Pathol Tox 10:99102.

López-Díaz TM, Román-Blanco C, García-Arias MT, García-Fernández MC, García-López ML, 1996. Mycotoxins in two Spanish cheese varieties. Int $\mathrm{J}$ Food Microbiol 30:391-5.

Moss MO, 1992. Secondary metabolism and food intoxication-moulds. J Appl Bacteriol 73:80-8.

Moubasher AH, Abdel-kader MJA, El-Kadi JA, 1978. Toxigenic fungi isolated from Roquefort cheese. Mycopathologia 66:18790.

0’Brien M, Nielsen KF, O'Kiely P, Forristal PD, Fuller HT, Frisvad JC, 2006. Mycotoxins and other secondary metabolites produced in vitro by Penicillium paneum Frisvad and Penicillium roqueforti Thom isolated from baled grass silage in Ireland. J Agr Food Chem 54:9268-76.

0'Connor TP, 0’Brien NM, 2000. Nutritional aspects of cheese. In: Fox PF, Guinee T, Cogan T, McSweeney P, eds. Fundamentals of cheese science. Aspen Publ., New York, NY, USA, pp 504-13.

Ohmomo S, Sato T, Utagawa T, Abe M, 1975. Isolation of Festuclavine and three new indole alkaloids, roquefortine A,B and C from cultures of Penicillium roqueforti. $\mathrm{J}$ Agr Chem Soc Jpn 49:615-23.

Pattono D, Grosso A, Stocco P, Pazzi M, Zeppa G, 2013. Survey of the presence of patulin and ochratoxin $\mathrm{A}$ in traditional semihard cheeses. Food Control 33:54-7.

Polonelli L, Lauriola L, Morace G, 1982. Preliminary studies on the carcinogenic effects of Penicillium roqueforti (PR toxin) on rats. Mycopathologia 78:125-7.

Pose G, Ludemann V, Gomez A, Segura J, 2007. Comparison of growth characteristics and roquefortine $\mathrm{C}$ production of Penicillium roqueforti from blue-veined cheese. Mycotoxin Res 23:122-6.

Puel 0, Tadrist S, Delaforge M, Oswald IP, 
Lebrihi A, 2007. The inability of Byssochlamys fulva to produce patulin is related to absence of 6-methylsalicylic acid synthase and isoepoxydon dehydrogenase genes. Int J Food Microbiol 115:31-9.

Sansing GA, Lillehoj EB, Detroy RW, Miller MA, 1976. Synergistic toxic effects of citrinin, ochratoxin A and penicillic acid in mice. Toxicon 14:213-20.

Schmidt-Heydt M, Magan N, Geisen R, 2008. Stress induction of mycotoxin biosynthesis genes by abiotic factors. FEMS Microbiol Lett 284:142-9.

Schoch U, Luthy J, Schlatter C, 1984a. Mutagenitatsprufung industriell verwendeter P. Camembert und P. roqueforti stamme. Z Lebensm Unters For 178:351-5.

Schoch U, Luthy J, Schlatter C, 1984b. Mykotoxine von $P$. roqueforti and $P$. camemberti in Kase. Milchwissenschaft 39:76-80.

Schumacher DM, Müller C, Metzler M, Lehman L, 2006. DNA-DNA crosslinks contribute to the mutagenic potential of the mycotoxin patulin. Toxicol Lett 166:268-75.

Scott PM, 1984. PR toxin. In: Betina V, ed. Mycotoxins production, isolation, separation and purification. Elsevier, Amsterdam, The Netherlands, pp 469-74.

Scott PM, Kanhere SR, 1979. Instability of PR toxin in blue cheese. J AOAC Int 62:141-7.

Scott PM, Kennedy BPC, 1976. Analysis of blue cheese for roquefortine and others alkaloids from Penicillium roqueforti. J Agr Food Chem 24:865-8.

Siemens K, Zawistowski J, 1992. Determination of Penicillium roqueforti toxin by reversed-phase HPLC. J Chromatogr 609:205-11.

Tiecco G, 2001. Igiene e tecnologia alimentare. Il Sole 24 ore Edagricole, Milano, Italy.

Usleber EM, Dade E, Schneider R, Dietrich J, Bauer E, Märtlbauer E, 2008. Enzyme immunoassay for mycophenolic acid in milk and cheese. J Agr Food Chem 56:6857-62.

Van Egmond HP, 1989. Mycotoxins in dairy products. Elsevier, London, UK.
Ware GM, Thorpe CW, Pohland AE, 1980. Determination of roquefortine in blue cheese and blue cheese dressing by high performance liquid chromatography with ultraviolet and electrochemical detectors. J AOAC Int 63:637-41.

Wei RD, Lee WYH, Wei YH, 1985. Some biochemical responses to PR toxin, a mycotoxin from Penicillium roqueforti. In: Lacey J, ed. Trichothecenes and other mycotoxins. Wiley and Sons Inc., New York, USA, pp 337-48.

Wei Yun JT, Liewen MB, Bullerman LB, 1988. Toxicity and sorbate sensitivity of moulds isolated from surplus commodity cheeses. J Food Protect 51:457-62.

Zambonin CG, Monaci L, Aresta A, 2002. Solidphase microextraction-high performance liquid chromatography and diode array detection for the determination of mycophenolic acid in cheese. Food Chem 78:249-54. 